\title{
Circular RNA TADA2A promotes proliferation and migration via modulating of miR-638/KIAA0101 signal in non-small cell lung cancer
}

\author{
YE ZHANG ${ }^{1}$, HONGMIN YAO $^{1}$, YING LI $^{1}$, LU YANG $^{2}$, LIANG ZHANG $^{3}$, \\ JINXIN CHEN ${ }^{4}$, YONG WANG ${ }^{5}$ and XIA LI ${ }^{1}$

\begin{abstract}
${ }^{1}$ Department of Radiation Oncology, Cancer Hospital of China Medical University/Liaoning Cancer Hospital and Institute;
${ }^{2}$ First Department of Gastroenterology, Cancer Hospital of China Medical University/Liaoning Cancer Hospital and Institute; Departments of ${ }^{3}$ Breast Internal Medicine and ${ }^{4}$ Gynecological Oncology, Cancer Hospital of China Medical University/ Liaoning Cancer Hospital and Institute, Dadong, Shenyang, Liaoning 110042; ${ }^{5}$ Central Laboratory, Central Hospital Affiliated to Shenyang Medical College, Dadong, Shenyang, Liaoning 110024, P.R. China
\end{abstract}

Received October 10, 2020; Accepted April 12, 2021

DOI: $10.3892 /$ or.2021.8152

\begin{abstract}
Accumulating evidence indicates that circular (circ)RNAs exhibit complex functions in diverse malignant tumors, including non-small cell lung cancer (NSCLC). The role of the circRNA transcription adaptor 2A (circTADA2A) in NSCLC remains unclear. The expression, function and mechanism of circTADA2A in NSCLC development were investigated in the present study. The results revealed that circTADA2A was upregulated in NSCLC, and that knockdown of circTADA2A inhibited cell proliferation and migration in the NSCLC cell lines A549 and H1299. Functional assays demonstrated that circTADA2A promoted proliferation and migration via interacting with microRNA (miR)-638. Bioinformatics and reverse transcription-quantitative PCR assay confirmed that miR-638 was expressed at low levels in NSCLC. In addition, it was found that miR-638 served a tumor-suppressive role and suppressed proliferation and migration via PCNA clamp associated factor (KIAA0101) inhibition in A549 and H1299 cells. Lastly, it was verified that circTADA2A promoted cell proliferation and migration, at least partially, via miR-638/KIAA0101 signaling in A549 and H1299 cells. In summary, the present study showed that circTADA2A promoted NSCLC cell proliferation and migration via modulating miR-638/KIAA0101 signaling.
\end{abstract}

Correspondence to: Dr Xia Li, Department of Radiation Oncology, Cancer Hospital of China Medical University/Liaoning Cancer Hospital and Institute, 44 Xiaoheyan Road, Dadong, Shenyang, Liaoning 110042, P.R. China

E-mail: doclixia@163.com

Key words: circular RNA transcription adaptor 2A, microRNA-638, PCNA clamp associated factor, proliferation, migration, non-small cell lung cancer

\section{Introduction}

As the most common cause of cancer-associated mortality worldwide, lung cancer accounted for $\sim 18.4 \%$ of all cancer-associated mortality in 185 countries in 2018 (1). Small cell lung cancer (SCLC) and non-SCLC (NSCLC) are the two primary types of lung cancer. NSCLC accounts for $\sim 85 \%$ of all histological subtypes of lung cancer (2). Despite improvements in surgical resection, chemotherapy, targeted therapy and radiotherapy, the prognosis of NSCLC remains unfavorable, since it presents with locally advanced or metastatic disease in $\sim 70 \%$ of patients at time of diagnosis (2). Therefore, it is urgent to identify new molecules and clarify their functions in NSCLC.

PCNA clamp associated factor (KIAA0101) is located on human chromosome $15 \mathrm{q} 22.31$ and contains five exons. KIAA0101 has been found to serve an oncogenic role in cancer (3-6). Fan et al (7) reported that KIAA0101 is a key promoter of renal cell carcinoma malignancy induced by erythropoietin. Lv et al (4) found that KIAA0101 knockdown suppresses cell growth, colony formation and $G_{1} / S$ phase transition in breast cancer cells. To the best of our knowledge, there is limited research on KIAA0101 and NSCLC. By analyzing 357 NSCLC tissue microarrays via immunohistochemical staining, Kato et al (8) found that KIAA0101 is highly expressed in $33.9 \%$ (121 of 357) of cases, and that overexpression of KIAA0101 predicted poor prognosis in patients with NSCLC. However, the detailed mechanism of KIAA0101 in NSCLC remains largely unknown.

Previously, circular (circ)RNAs have attracted increasing attention in non-coding RNA research $(9,10)$. circRNAs are a group of stable, covalently closed RNAs transcripts with gene-regulatory potential (11). circRNAs serve pivotal regulatory roles, and can be valuable diagnostic and prognostic biomarkers in NSCLC (12). The function of circRNA transcriptional adaptor 2A (TADA2A; circTADA2A; also named hsa_circ_0043278 in circBase) in cancer remains controversial. 
circTADA2A serves as a tumor suppressor in several types of malignancy, including breast and colorectal cancer $(13,14)$. Wu et al (15) reported that circTADA2A competes with cyclic AMP-responsive element-binding protein 3 (CREB3) via similar microRNA (miRNA/miR)-203a-3p response elements and promotes cancer progression and metastasis in osteosarcoma. However, the role of circTADA2A in NSCLC remains largely unknown.

The present study investigated the expression and function of circTADA2A and its potential oncogenic role in NSCLC.

\section{Materials and methods}

Patients and tissue samples. A total of 60 NSCLC (38 males and 22 females; age, 49-83 years; mean age, 61.7 years) and paired paratumor tissue specimens ( $2 \mathrm{~cm}$ from NSCLC tissue) were collected from patients following surgical resection between January 2015 and April 2018 at Liaoning Cancer Hospital and Institute (Shenyang, China). All patients provided written informed consent, and the study was performed in accordance with the Declaration of Helsinki. Approval of the study was granted by the Institute Research Medical Ethics Committee of Liaoning Cancer Hospital \& Institute. All patients were histologically diagnosed by two pathologists, and classified as stage I, II, III or IV, using the Tumor-Node-Metastasis (TNM) staging system (version 8) (16).

Cell culture. The human NSCLC (A549, H460, H1299 and H1975) and normal bronchial epithelial cell line 16HBE were purchased from the Institute of Biochemistry and Cell Biology of the Chinese Academy of Sciences. The 16HBE cells were cultured in Airway Epithelial Cell Basal Medium (American Type Culture Collection); NSCLC cell lines were cultured in Dulbecco's modified Eagle medium (Gibco; Thermo Fisher Scientific, Inc.). All media were supplemented with $10 \%$ FBS (Thermo Fisher Scientific, Inc.). All cells were incubated at a constant temperature of $37^{\circ} \mathrm{C}$ in a humidified atmosphere containing $5 \% \mathrm{CO}_{2}$.

Bioinformatics and GEO database analysis. CircPrimer (17) was used to compare the nucleotide sequences of circTADA2A and TADA2A mRNA. The clinical value of miR-632-targeted genes in The Cancer Genome Atlas was analyzed using online software UALCAN (18). Data on differentially expressed circRNAs (ncbi.nlm.nih. gov/geo/query/acc.cgi?acc=GSE101586), miRNAs (ncbi. nlm.nih.gov/geo/query/acc.cgi?acc=GSE19945 and ncbi. nlm.nih.gov/geo/query/acc.cgi?acc=GSE74190) and mRNAs in NSCLC were downloaded from the GEO database (ncbi. nlm.nih.gov/geo/query/acc.cgi?acc=GSE19188 and ncbi.nlm. nih.gov/geo/query/acc.cgi?acc $=$ GSE30219). Differentially expressed circRNAs, miRNAs and mRNAs were analyzed using the online software GEO2R (19).

RNase $R$ treatment. In order to detect the stability of circTADA2A, RNase $\mathrm{R}$ assay was performed as previously described (15). A total of $5 \mathrm{U} / \mu \mathrm{g}$ RNase R (Epicentre; Illumina, Inc.) was added to $2 \mathrm{mg}$ total RNA (isolated from A549 or H1299 cells) and incubated for $30 \mathrm{~min}$ at $37^{\circ} \mathrm{C}$. Controls were untreated. Subsequently, RNeasy MinElute
Cleaning kit (Qiagen, Inc.) was applied to purify the RNAs according to the manufacturer's instructions. Next, reverse transcription-quantitative (RT-q)PCR was performed to detect circRNAs or mRNAs.

Actinomycin D assay. Actinomycin D assay was performed as previously reported (20). Briefly, $2 \mu \mathrm{g} / \mathrm{ml}$ actinomycin D (Sigma-Aldrich; Merck KGaA) was added to A549 and $\mathrm{H} 1299$ cells and incubated at $37^{\circ} \mathrm{C}$ for $4,8,12$ and $24 \mathrm{~h}$. Next, total RNA from A549 or H1299 cells was extracted, and the levels of circTADA2A and linear TADA2A mRNA were measured by RT-qPCR.

$R N A$ extraction and $R T-q P C R$. RNA extraction and RT-qPCR were performed as previously described (21). Total RNA from CRC tissue and cells was extracted using TRIzol ${ }^{\circledR}$ reagent (Invitrogen; Thermo Fisher Scientific, Inc.) according to the manufacturer's protocol. To qualify the level of circTADA2A, RNase R (3 U/1,000 ng; Epicentre; Illumina, Inc.) was added to digest linear RNAs during RNA extraction and incubated for $10 \mathrm{~min}$ at $37^{\circ} \mathrm{C}$. A total of $500 \mathrm{ng}$ RNA was reverse transcribed into cDNA using a Goscript ${ }^{\mathrm{TM}}$ Reverse Transcription system (Promega Corporation) according to the manufacturer's instructions. Stem-loop RT was performed for miR-638 using the TaqMan MicroRNA detection kit (Thermo Fisher Scientific, Inc.). Then, qPCR was performed using SYBR Premix Ex Taq II (Takara Bio, Inc.). $\beta$-actin and U6 were employed as endogenous controls for mRNA and miR-637, respectively. PCR amplification conditions were as follows: $2 \mathrm{~min}$ at $95^{\circ} \mathrm{C}$ for one cycle, followed by denaturation for $15 \mathrm{sec}$ at $95^{\circ} \mathrm{C}$ and extension for $60 \mathrm{sec}$ at $60^{\circ} \mathrm{C}$ for 38 cycles. The relative expression levels of the genes were determined using the $2^{-\Delta \Delta \mathrm{Cq}}$ method (16). The primer sequences are listed in Table I.

Western blot analysis. Western blotting was performed as previously reported (21). Total protein from A549 and H1299 cells was extracted using radio immunoprecipitation assay lysis buffer (Sigma-Aldrich; Merck KGaA) and quantified by BCA kit (Santa Cruz Biotechnology, Inc.). Total proteins $(20 \mu \mathrm{g})$ were separated by $10 \%$ SDS-PAGE and transferred onto PVDF membranes (EMD Millipore), which was blocked with 5\% BSA (Sigma-Aldrich; Merck KGaA) for $1 \mathrm{~h}$ at room temperature. Primary anti bodies against KIAA0101 (1:1,000; cat.no. ab226255; Abcam) and GAPDH (1:500; cat.no. ab8245; Abcam) were then added to the membranes and incubated at $4^{\circ} \mathrm{C}$ overnight. Next, a secondary antibody [horseradish peroxidase (HRP)-conjugated goat anti-mouse IgG; $1: 2,000$; cat. no. ab205719; Abcam] was added to the membranes and incubated at $24^{\circ} \mathrm{C}$ for $1 \mathrm{~h}$. Signals of the targeted proteins were detected using an ECL Western Blotting Substrate kit (cat. no. ab65623; Abcam) and bands were analyzed with Image J software version 2 (National Institutes of Health).

Plasmids and oligonucleotide transfection. Specific small interfering (si)RNAs targeting circTADA2A and KIAA0101 and scramble control siRNAs (siSCRs) were purchased from Shanghai GenePharma Co., Ltd. miR-638 mimics and miR-negative control (NC), as well as miR-638 inhibitor (inh) and inh-NC were purchased from Shanghai GenePharma Co., Ltd. circTADA2A overexpression plasmids containing miR-638 
binding sequences (oecircTADA2A) were also synthesized by Shanghai GenePharma Co., Ltd. When cells reached 80-90\% confluence, $5 \mathrm{~nm}$ miR-638 mimics/inhibitors and $50 \mathrm{nM}$ siRNAs were transfected into A549 and H1299 cells using Lipofectamine ${ }^{\circledR} 3000$ (Invitrogen; Thermo Fisher Scientific, Inc.) according to the manufacturer's instructions at room temperature. Subsequent experiments were performed $24 \mathrm{~h}$ after transfection. Sequences of siRNAs, miR-638 mimics, miR-NC, miR-638 inhibitor and inh-NC are listed in Table I.

Cell Counting Kit-8 (CCK-8) assay. CCK-8 assay was performed as previously described (20). In brief, $2 \times 10^{3}$ A549 and H1299 cells were seeded into 96-well plates, and $200 \mu \mathrm{l}$ culture medium was added to each well. The cells were then incubated at $37^{\circ} \mathrm{C}$ with $5 \% \mathrm{CO}_{2}$. Following incubation for 1-5 days, each well was supplemented with $20 \mu \mathrm{l} \mathrm{CCK-8} \mathrm{solu-}$ tion (Dojindo Molecular Technologies, Inc.). Following $2 \mathrm{~h}$ incubation, a microplate reader (Bio-Rad Laboratories, Inc.) was used to measure the absorbance at $450 \mathrm{~nm}$. The assays were repeated three times.

Transwell chamber assay. Transwell assay was conducted as previously reported (22). For invasion assays, upper chambers (Corning, Inc.) were pre-coated with Matrigel (1:8; BD Biosciences) for $1 \mathrm{~h}$ at room temperature. A549 and H1299 cells $\left(5 \times 10^{4}\right)$ were incubated in the upper chambers. Serum-free DMEM was added to the upper chamber; medium in the lower chamber was filled with DMEM supplemented with $10 \%$ FBS and the cells were incubated at $37^{\circ} \mathrm{C}$ for $12 \mathrm{~h}$. After $12 \mathrm{~h}$, non-migratory cells were removed and while migratory or invasive A549 and H1299 cells were fixed with $4 \%$ paraformaldehyde at room temperature for $30 \mathrm{~min}$, stained with crystal violet at $25^{\circ} \mathrm{C}$ for $1 \mathrm{~min}$ and counted using an inverted microscope (Olympus Corporation).

RNA fluorescence in situ hybridization (FISH). The assay was performed as previously described (20). Specific probes targeting circTADA2A or miR-638 were synthesized by Shanghai GenePharma Co., Ltd. The assay was conducted using a FISH kit (Shanghai GenePharma Co., Ltd.) according to the manufacturer's instructions. Cy3-labeled circTADA2A and Dig-labeled locked nucleic acid miR-638 probes (Shanghai GenePharma Co., Ltd.) were measured using the aforementioned FISH kit, followed by visualization with a confocal microscope (Carl Zeiss AG).

Immunohistochemistry (IHC). IHC assay was performed using a specific HRP/DAB (ABC) Detection IHC kit (Abcam) as previously described (23). NSCLC tissues were sliced following $4 \%$ paraformaldehyde fixation for $4 \mathrm{~h}$ at room temperature, $10 \%$ EDTA (pH, 7.3) decalcification, dehydration and paraffin embedding. Then, the tissue sections $(4-\mu \mathrm{m}$ thick) were incubated with anti-KIAA0101 antibody (1:500; cat.no. ab226255; Abcam) at $4^{\circ} \mathrm{C}$ overnight. The tissue sections were incubated with secondary antibodies $(1: 1,000$; cat. no. E043201; Dako; Agilent Technologies, Inc.) at $37^{\circ} \mathrm{C}$ for $30 \mathrm{~min}$. Subsequently, the tissue sections were incubated with streptavidin HRP for another $30 \mathrm{~min}$ at room temperature (Labeled Streptavidin Biotin kit; cat. no. K060911-8; Dako; Agilent Technologies, Inc) at room temperature and
Table I. Primer and oligonucleotide sequences.

A, Primers

\begin{tabular}{ll}
\hline Name & \multicolumn{1}{c}{ Sequence, ' $\rightarrow 3 '^{\prime}$} \\
\hline circTADA2A & F: TGTGCACCAAGACCAAGGAG \\
& R: AGGAAAATCTGAAGTAGTGA \\
circNOL10 & F: TGCTTCTGACGGCCAATGAA \\
& R: AACAGGCCAACTCTGTTTCGA \\
TADA2A & F: CCCAAAAATATATGTGAAGGCCA \\
& R: AAGCAGTTTGCAAAGGAAACAG \\
KIAA0101 & F: TCAGTTCGTTCTCTCCTCTCC \\
$\beta$-actin & R: TAGTGGCAGAGGTGGAAGAAC \\
miR-638 & F: CTTCTACAATGAGCTGCGTG \\
& F: TCATGAGGTAGTCAGTCAGG \\
U6 & R: TGCTAGGGATCGCGGGCGGGTG \\
& F: CTCGCTTCGGCAGCACA \\
& R: AACGCTTCACGAATTGCGT \\
\hline
\end{tabular}

B, Oligonucleotides

\begin{tabular}{ll}
\hline Name & \multicolumn{1}{c}{ Sequence, $5^{\prime} \rightarrow 3^{\prime}$} \\
\hline sicircTADA2A-1 & CCAUUUCACUGCAGGAUGU dTdT \\
sicircTADA2A-2 & CACUGCAGGAUGUAGCCAA dTdT \\
siSCR & UUCUCCGAACGUGUCACGUTT \\
miR-638 & AGGGAUCGCGGGCGGGUGGGCGGC \\
mimics & CU \\
miR-638 & AGGCCGCCCACCCGCCCGCGAUCC \\
inhibitor & CU \\
miR-NC & CAGUACUUUUGUGUAGUACAA \\
\hline
\end{tabular}

circTADA2A, circular RNA transcription adaptor 2A; NOL10, nucleolar protein 10; KIAA0101, PCNA clamp associated factor; miR, microRNA; si, small interfering; SCR, scramble; NC, negative control; F, forward; R, reverse.

stained with $0.05 \%$ 3,3-diaminobenzidine for $60 \mathrm{sec}$ at room temperature. Finally, the slides were counterstained with $10 \%$ hematoxylin for $3 \mathrm{~min}$ at room temperature, dehydrated in a graded ethanol series (absolute ethyl alcohol for $3 \mathrm{~min}, 95 \%$ ethanol for $3 \mathrm{~min}$ and $85 \%$ ethanol for $3 \mathrm{~min}$ ), then observed under a light microscope.

Dual luciferase reporter assay. Reporter plasmids containing wild-type (wt) or mutant (mut) circTADA2A sequences (luc-circTADA2A-wt and luc-circTADA2A-mut), as well as reporter plasmids containing wt or mut KIAA0101 sequences (luc-KIAA0101-wt and luc-KIAA0101-mut) were synthesized by Shanghai GenePharma Co., Ltd. The procedures were performed as previously described (15). When A549 and H1299 cells reached 70\% confluence, reporter plasmids and miR-638 mimics or miR-NC were co-transfected into A549 and H1299 cells using Lipofectamine ${ }^{\circledR} 3000$ (Invitrogen; Thermo Fisher Scientific, Inc.). After 48 h, luciferase activity 
Table II. Association between circTADA2A and clinicopathological characteristics of patients with non-small cell lung cancer.

\begin{tabular}{|c|c|c|c|c|}
\hline \multirow[b]{2}{*}{ Characteristic } & \multirow[b]{2}{*}{ Cases $(n=60)$} & \multicolumn{2}{|c|}{ circTADA2A expression } & \multirow[b]{2}{*}{ P-value } \\
\hline & & High & Low & \\
\hline Age, years & & & & 0.791 \\
\hline$\leq 60$ & 23 & 12 & 11 & \\
\hline$>60$ & 37 & 18 & 19 & \\
\hline Sex & & & & 0.284 \\
\hline Male & 38 & 21 & 17 & \\
\hline Female & 22 & 9 & 13 & \\
\hline Smoking history & & & & 0.787 \\
\hline Yes & 39 & 19 & 20 & \\
\hline No & 21 & 11 & 10 & \\
\hline Pathology & & & & 0.301 \\
\hline Adenocarcinoma & 28 & 16 & 12 & \\
\hline Squamous carcinoma & 32 & 14 & 18 & \\
\hline TNM stage & & & & 0.038 \\
\hline $\mathrm{I}+\mathrm{II}$ & 28 & 10 & 18 & \\
\hline III + IV & 32 & 20 & 12 & \\
\hline Lymph node metastasis & & & & 0.001 \\
\hline Yes & 38 & 25 & 13 & \\
\hline No & 22 & 5 & 17 & \\
\hline Tumor size, $\mathrm{cm}$ & & & & 0.020 \\
\hline$\leq 3$ & 29 & 10 & 19 & \\
\hline$>3$ & 31 & 20 & 11 & \\
\hline
\end{tabular}

Data were analyzed by Pearson Chi-square or Fisher's exact test. circTADA2A, circular RNA transcription adaptor 2A.

was measured and compared with Renilla luciferase activity using the Dual-Luciferase Reporter Assay system (Promega Corporation) according to the manufacturer's protocol.

RNA immunoprecipitation (RIP) assay. RIP assay was performed as previously reported (24) using a Magna RIP RNA-Binding Protein Immunoprecipitation kit (EMD Millipore). Argonaute (Ago)2 plasmid or vector were transfected into A549 and H1299 cells. Subsequently, RIP Lysis Buffer combined with a protease inhibitor cocktail and RNase inhibitors was used to lyse A549 and H1299 cells. Cell lysates $(200 \mu \mathrm{l})$ were incubated with $5 \mu \mathrm{g}$ antibody against Ago2 (EMD Millipore) or rabbit IgG-coated beads at $4^{\circ} \mathrm{C}$ overnight with rotation. RNeasy MinElute Cleanup kit (Qiagen, Inc.) was used to extract the immunoprecipitated RNA and extracted RNAs were reverse transcribed and subjected to qPCR to detect the abundance of circTADA2A.

RNA pull-down assay. The targeted binding effect between circTADA2A and miR-638 was verified by RNA pull-down assay as previously reported (25). Biotinylated miR-638 probe was purchased from Shanghai GenePharma Co., Ltd. A549 and H1299 cells $\left(1 \times 10^{6}\right)$ were harvested, lysed by $200 \mu 1$ Pierce ${ }^{\circledR}$ IP lysis buffer (Thermo Fisher Scientific, Inc.) and sonicated. The pull-down assay was performed using a Pierce $^{\mathrm{TM}}$ Magnetic RNA-Protein Pull-Down kit (Thermo
Fisher Scientific, Inc.) according to the manufacturer's instructions. In brief, $50 \mu \mathrm{l}$ - 1 magnetic beads (Thermo Fisher Scientific, Inc.) were co-incubated with 50 pmol biotinylated miR- 638 or $\mathrm{NC}$ probes at $25^{\circ} \mathrm{C}$ for $30 \mathrm{~min}$ to generate probe-coated beads. The beads were harvested by a magnetic stand (Thermo Fisher Scientific, Inc.), then incubated with cell lysate at $4^{\circ} \mathrm{C}$ for $60 \mathrm{~min}$. The beads were harvested using a magnetic separation stand (Thermo Fisher Scientific, Inc.). The pulled down RNA complexes were eluted and extracted using a RNeasy Mini kit (Qiagen, Inc.), Pulled down circTADA2A and circular nucleolar protein 10 (NOL10) were determined by RT-qPCR, as aforementioned.

Statistical analysis. All data are presented as the mean \pm SD $(n=3)$. Statistical analysis was performed with GraphPad Prism v5.0 (GraphPad Software, Inc.) and SPSS 19.0 statistical software (IBM Corp.). Survival analysis was performed by Kaplan-Meier analysis using log-rank test. The clinical value of circTADA2A was measured by receiver operating characteristic (ROC) curve analysis. The association between circTADA2A and miR-638 was analyzed by Spearman correlation analysis. For comparison of two groups, $\chi^{2}$ or paired Student's $t$ test were performed. For the comparison of multiple groups, one-way ANOVA followed by post hoc Dunnett's or Tukey's multiple comparisons test were performed, as appropriate. $\mathrm{P}<0.05$ was considered to indicate a statistically significant difference. 


\section{Results}

circTADA2A is upregulated in patients with NSCLC. By analyzing the profile of circRNA expression in five lung adenocarcinoma and paired normal lung tissue samples from a genome-wide study (GSE101586), it was found that 22 upregulated circRNAs and 17 downregulated circRNAs were significantly differentially expressed in lung cancer compared with normal tissue (cut-off criteria: $\mathrm{P}<0.05$ and $\mid \log \mathrm{FCl} \geq 1.2$; Fig. 1A; Table SI). circTADA2A (probe ID: ASCRP002384; circBase ID: hsa_circ_0043278) was selected for further study since it was the most significantly upregulated circRNA (Fig. 1B; Table SI). The expression of circTADA2A was determined in 60 NSCLC tissue specimens and cell lines. circTADA2A was upregulated in NSCLC tissue specimens and cell lines (Fig. 1C and D). Additionally, it was uncovered that the changes of circTADA2A in A549 and H1299 were more significantly than in H460 and H1975 cells. A549 and H1299 were selected for use in subsequent experiments. In comparison with its parental gene, circTADA2A was found to form a covalently closed continuous loop, and comprised exons 5 and 6 of the TADA2A gene, using the online software CircPrimer (17) (Fig. 1E). RNase R and actinomycin D assays were performed to detect the stability of circTADA2A. circTADA2A was more stable than its parental TADA2A mRNA following treatment with RNase $\mathrm{R}$ and actinomycin D (Fig. 1F-I).

Upregulated circTADA2A predicts aggressive clinicopathological characteristics and poor prognosis in patients with NSCLC. In order to determine the clinical role of circTADA2A, the association between circTADA2A expression levels and clinicopathological characteristics of patients with NSCLC was analyzed. Higher levels of circTADA2A were more frequently observed in patients with lymph node metastasis and advanced stage disease (Fig. 2A and B). Furthermore, high expression of circTADA2A was associated with clinicopathological characteristics of patients with NSCLC, particularly TNM stage and lymph node metastasis. (Table II). Kaplan-Meier analysis indicated that patients with NSCLC who had a higher circTADA2A level had poorer overall survival (Fig. 2C). circTADA2A may be a valuable biomarker in NSCLC according to the results of ROC curve analysis (area under the curve $=0.8606$; Fig. 2D).

circTADA2A suppression inhibits proliferation and migration of A549 and H1299 cells. In order to evaluate the role of circTADA2A on proliferation and migration of NSCLC cells, siRNAs targeting the back-splice sites were used to knock down expression of circTADA2A in A549 and H1299 cells. circTADA2A was significantly knocked down, while TADA2A mRNA was not changed following transfection with circTADA2A siRNAs (Fig. 3A and B). sicircTADA2A-1 was selected as the silencing tool for subsequent experiments as it exhibited the greatest efficacy. Next, the proliferation, migration and invasion of A549 and H1299 cells were detected following knockdown of circTADA2A. The results indicated a significant delay in the proliferation, migration and invasion of A549 and H1299 following knockdown of circTADA2A compared with cells transfected with siSCR (Fig. 3C-F).
circTADA2A serves as a sponge for $m i R-638$. circRNAs have been reported to exert their functions by acting as miRNAs sponges in various cancer types (26). It was hypothesized that circTADA2A functions via a similar mechanism in NSCLC. circTADA2A was primarily located in the cytoplasm of A549 and H1299 cells (Fig. 2E and F). RIP assay showed that circTADA2A was significantly enriched in Ago2 protein (Fig. 4A). Online prediction software Circular RNA Interactome (27), was used to predict potential miRNAs that may interact with circTADA2A. A total of 8 potential miRNAs that could bind to circTADA2A were found (Table SII). Among them, only miR-638 was expressed at low levels in NSCLC tissue according to genome-wide studies using GSE74190 and GSE19945 datasets (Fig. 4B-D, and Tables SIII and SIV). Furthermore, miR-638 was expressed at low levels in NSCLC tissue and cells (Fig. 4E and F). Additionally, an inverse correlation between circTADA2A and miR-638 was observed (Fig. 4G). RNA FISH assay indicated that circTADA2A and miR-638 co-localized in the cytoplasm (Fig. 4H). A luciferase reporter assay was conducted to confirm the targeted binding effect between circTADA2A and miR-638. Compared with that of miR-NC, miR-638 mimic significantly decreased luciferase reporter activity (Fig. 4I and J). When the predictive target sites for miR-638 were mutated, the change in luciferase activity was insignificant. Ago RISC catalytic component 2 (AGO2) is a key RNA binding protein for the ceRNA theory of RNA-RNA interactions among miRNAs, long non-coding RNAs and circRNAs (28-30). In order to determine the mechanism of circTADA2A, RIP assay was performed, using IgG as a control. The enriched circTADA2A and circNOL10 [a circRNA reported not to bind to Ago2 (31)] were analyzed. The results indicated that, compared with the NC probe, circTADA2A but not circNOL10 was pulled down by the miR-638 probe (Fig. $4 \mathrm{~K}$ and L). Lastly, it was observed that circTADA2A was not affected by up- or downregulation of miR-638. Similarly, the level of miR-638 was not affected either by up- or downregulation of circTADA2A (Fig. 4M and N).

miR-638 suppresses cell proliferation and migration by targeting KIAAO1O1 in A549 and H1299 cells. In order to identify the downstream genes of miR-638, the online prediction results of TargetScan (32) and upregulated genes according to two genome-wide studies, GSE19188 and GSE30219 (cut-off criteria: $\mathrm{P}<0.05$ and $\log \mathrm{FC}$ value $\geq 2$ ), were combined. It was found that four mRNAs, matrix metalloproteinase 1, BUB1 mitotic checkpoint serine/threonine kinase, KIAA0101 and steroid $5 \alpha$-reductase 1, overlapped (Fig. 5A; Tables SV-SVII). KIAA0101 has been reported to be implicated in NSCLC proliferation and metastasis (8). Among the aforementioned four genes, KIAA0101 was more closely correlated with shorter OS rate in lung cancer according to Kaplan-Meier analysis using the online software UALCAN (18) (Fig. S1). Therefore, KIAA0101 was selected for subsequent experiments. KIAA0101 was upregulated in NSCLC according to the results of IHC staining and genome-wide studies using GSE19188 and GSE30219 datasets (Fig. 5B-D). Furthermore, up- and downregulation of miR-638 inversely regulated KIAA0101 protein expression (Fig. 5E and F). Functionally, upregulation of miR-638 suppressed A549 and H1299 cell 

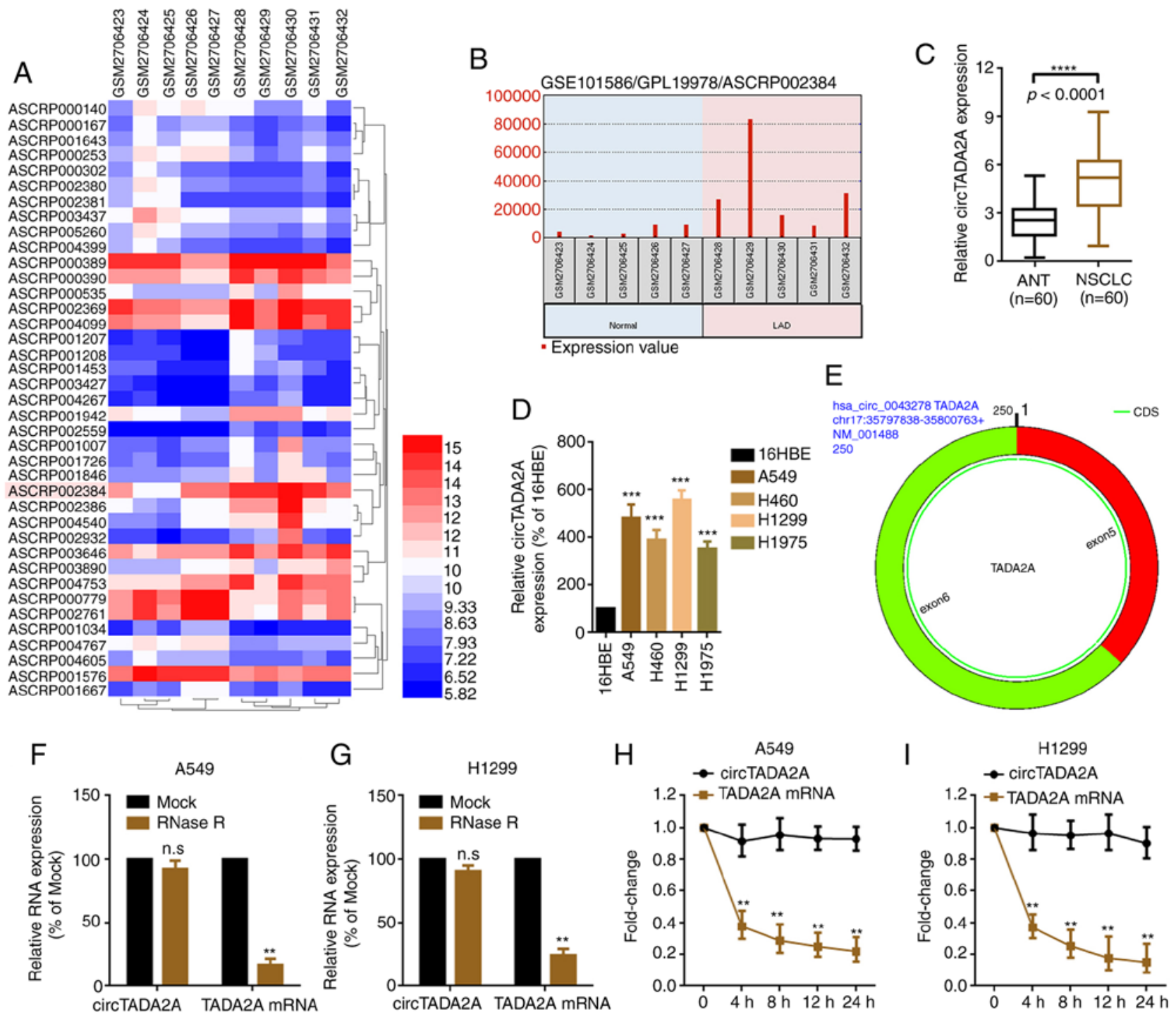

Figure 1. circTADA2A is upregulated in patients with NSCLC. (A) Differentially expressed circRNAs in five LAD and paired normal lung tissue samples, as illustrated by a heatmap $(\mathrm{P}<0.05$ and $\mid \log \mathrm{FCl} \geq 1.2)$. (B) circTADA2A was highly expressed in LAD compared with paired normal lung tissue. Probe ID ASCRP002384 represents circTADA2A. Expression of circTADA2A in (C) NSCLC and ANT and (D) cell lines was determined by RT-qPCR (n=38). ${ }^{* * *} \mathrm{P}<0.001$ vs. $16 \mathrm{HBE} ;{ }^{* * * * *} \mathrm{P}<0.0001$. (E) circTADA2A derives from exons 5 and 6 of linear TADA2A, as verified by the online software CircPrimer version 1.2 . A total of $5 \mathrm{U} / \mu \mathrm{g}$ RNase R was added to (F) A549 and (G) H1299 cells, and the mRNA expression of circTADA2A and TADA2A was evaluated by RT-qPCR A total of $2 \mathrm{mg} / \mathrm{ml}$ actinomycin D was added to (H) A549 and (I) H1299 cells, and the mRNA expression of circTADA2A and TADA2A was evaluated by RT-qPCR. ${ }^{* *} \mathrm{P}<0.01$ vs. Mock. All data are shown as the mean $\pm \mathrm{SD}(\mathrm{n}=3)$. circTADA2A, circular RNA transcription adaptor 2A; circRNA, circular RNA; NSCLC, non-small cell lung cancer; RT-q, reverse transcription-quantitative; ANT, adjacent non-tumor tissue; FC, fold change; LAD, lung adenocarcinoma.

proliferation and metastasis. When the level of KIAA0101 was elevated (following co-transfection of miR-638 mimic and specific KIAA0101 overexpression plasmids), the suppressive effect of miR-638 was abolished (Fig. 5G-J). Lastly, it was verified that KIAA0101 was a direct target of miR-638 via six base pair binding sites (positions 1,473-1,479; Fig. 5K-M).

circTADA2A promotes cell proliferation and migration partially via the miR-638/KIAA0101 pathway in A549 and $H 1299$ cells. The present study investigated whether the oncogenic role of circTADA2A in A549 and H1299 cell proliferation and migration was achieved, at least partially, via the miR-638/KIAA0101 signaling pathway. The protein expression of KIAA0101 following overexpression or knockdown of circTADA2A was analyzed by western blotting. Overexpression of circTADA2A positively regulated
KIAA0101 protein expression and vice versa (Fig. 6A and B). circTADA2A sponged miR-638, and KIAA0101 was a downstream target of miR-638. The present study investigated whether circTADA2A regulated KIAA0101 via miR-638 sponging. circTADA2A promoted KIAA0101 protein expression; this effect was abolished by miR-638 mimics (Fig. S2A and B). CCK-8 assay demonstrated that overexpression of circTADA2A promoted the proliferation of A549 and H1299 cells; this effect was abrogated by miR-638 mimics (upregulation of miR-638; Fig. 6C and D). Similarly, overexpression of circTADA2A promoted migration and invasion of A549 and H1299 cells but this effect was attenuated by miR-638 mimics (Fig. 6E and F). Overall, the present study indicated that circTADA2A promoted cell proliferation and migration, at least partially, via the miR-638/KIAA0101 pathway in A549 and H1299 cells. 
A

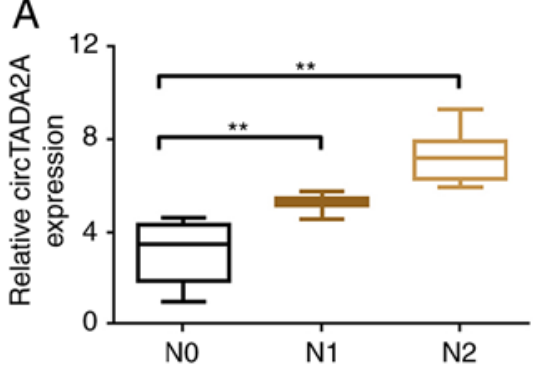

D

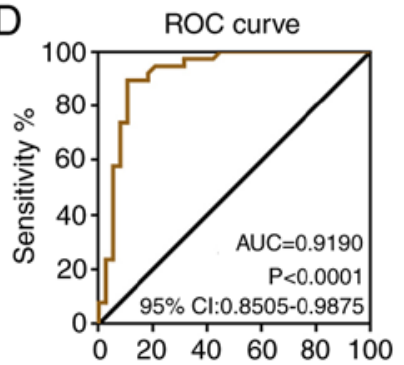

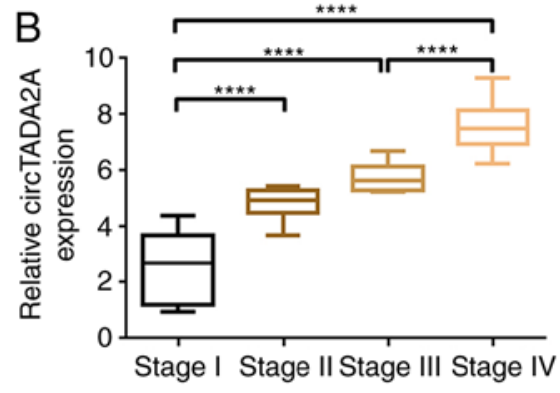

E

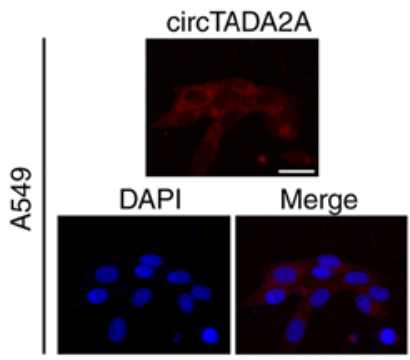

C

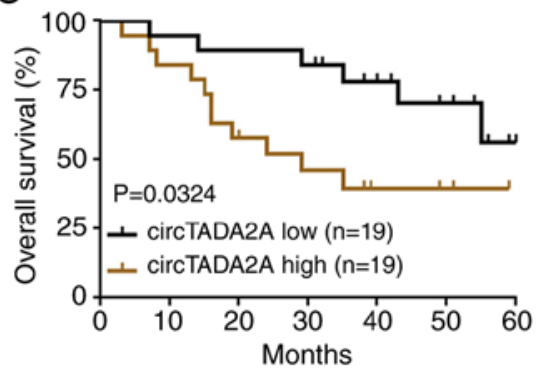

F

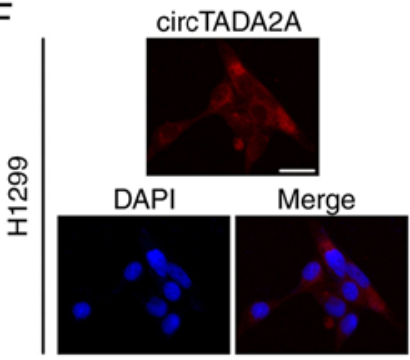

Figure 2. Upregulated circTADA2A predicts aggressive clinicopathological characteristics and poor prognosis in patients with NSCLC. (A) circTADA2A is upregulated in patients with (A) lymph node metastasis and (B) advanced TNM stage, as determined by reverse transcription-quantitative $\mathrm{PCR}$ assay. ${ }^{* *} \mathrm{P}<0.01$, ${ }^{* * * * *} \mathrm{P}<0.0001$. (C) Overall survival of patients with NSCLC and high levels of circTADA2A was shorter than that of patients with low levels of circTADA2A, as determined by Kaplan-Meier analysis. (D) Clinical value of circTADA2A in NSCLC was detected by ROC curve analysis. AUC=0.9190. Representative fluorescence in situ hybridization images indicated that circTADA2A was primarily located in the cytoplasm of (E) A549 and (F) H1299 cells. Scale bar, $50 \mu \mathrm{m}$. All data are presented as mean \pm SD $(\mathrm{n}=3)$. circTADA2A, circular RNA transcription adaptor 2A; NSCLC, non-small cell lung cancer; ROC, receiver operating characteristic.

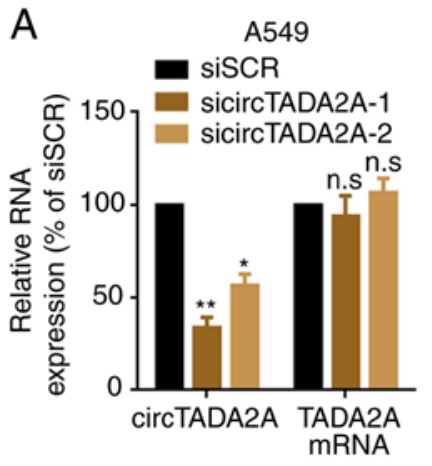

E

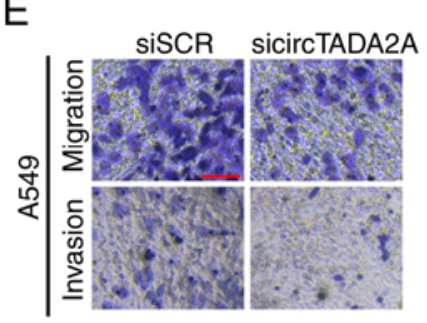

B
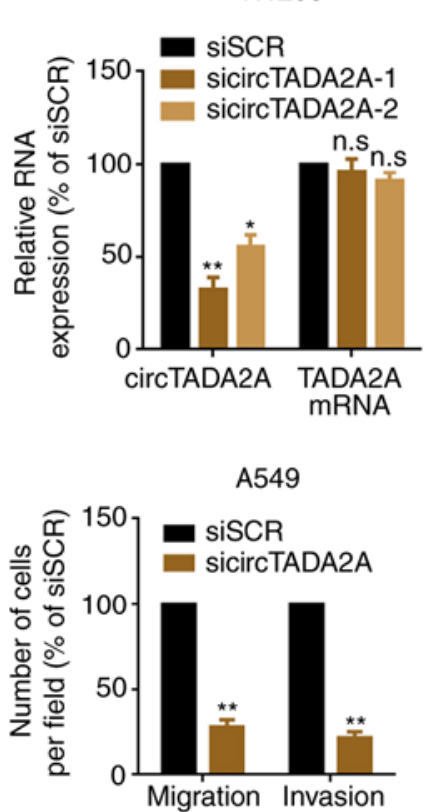

C

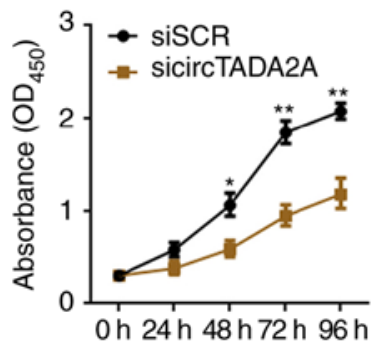

$\mathrm{F}$

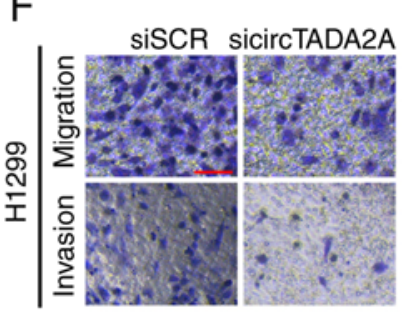

D $\quad \mathrm{H} 1299$

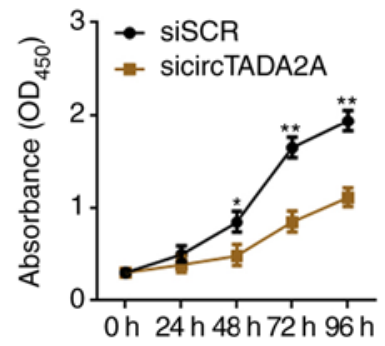

H1299

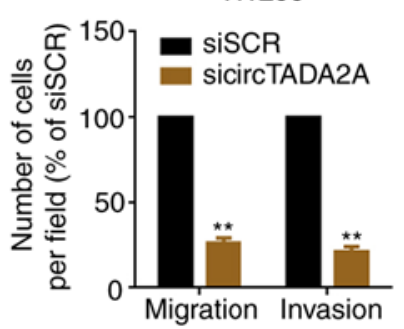

Figure 3. circTADA2A suppression inhibits proliferation and migration of A549 and H1299 cells. The expression of circTADA2A and linear TADA2A mRNA in (A) A549 and (B) H1299 cells following transfection with specific circTADA2A siRNAs was evaluated by reverse transcription-quantitative PCR. Cell proliferation was assessed in (C) A549 and (D) H1299 cells by Cell Counting Kit-8 assay. Migration and invasion of (E) A549 and (F) H1299 cells was evaluated by Transwell assay. Magnification, $\mathrm{x} 20$; scale bar, $200 \mu \mathrm{m}$. All data are shown as the mean $\pm \mathrm{SD}(\mathrm{n}=3)$. ${ }^{*} \mathrm{P}<0.05$, ${ }^{* *} \mathrm{P}<0.01 \mathrm{vs}$. siSCR. circTADA2A, circular RNA transcription adaptor 2A; si, small interfering; SCR, scramble; n.s., not significant; OD, optical density.

\section{Discussion}

Increasing evidence indicates that non-coding RNAs are involved in various human diseases, including cancer (33).
As a novel type of non-coding RNAs, circRNAs, which are abundant in the human transcriptome, exhibit diverse biological functions associated with their specific structural features (34-37).circTADA2A (circBase IDhsa_circ_0043278) 
A

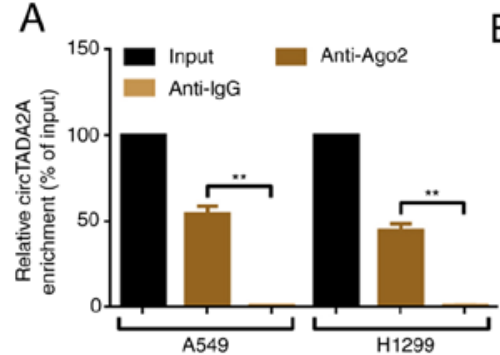

E

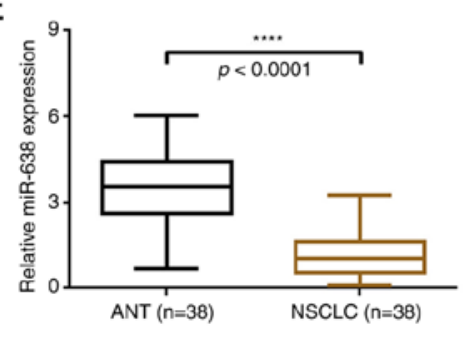

B

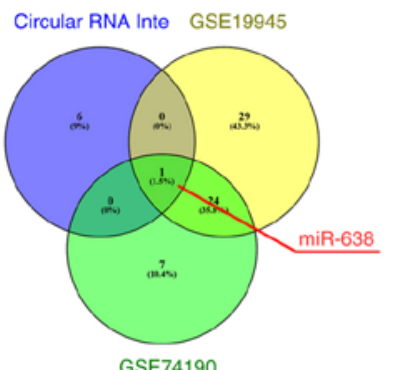

F

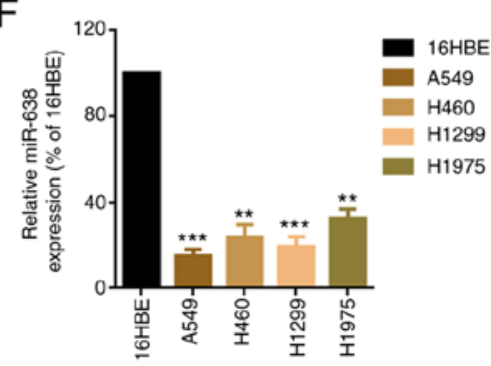

C

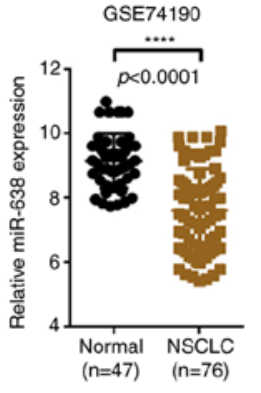

D

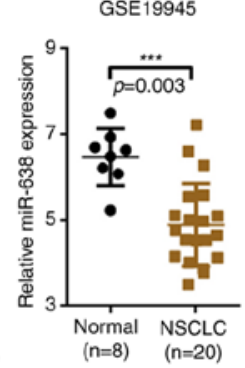

G

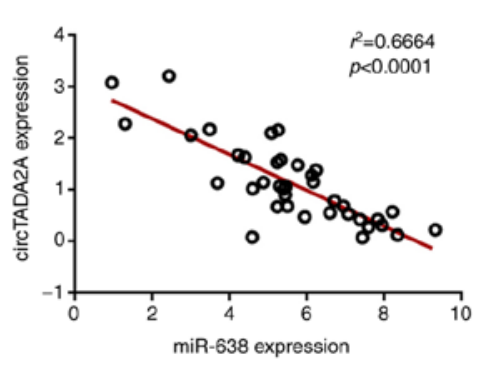

A549

$\mathrm{H}$
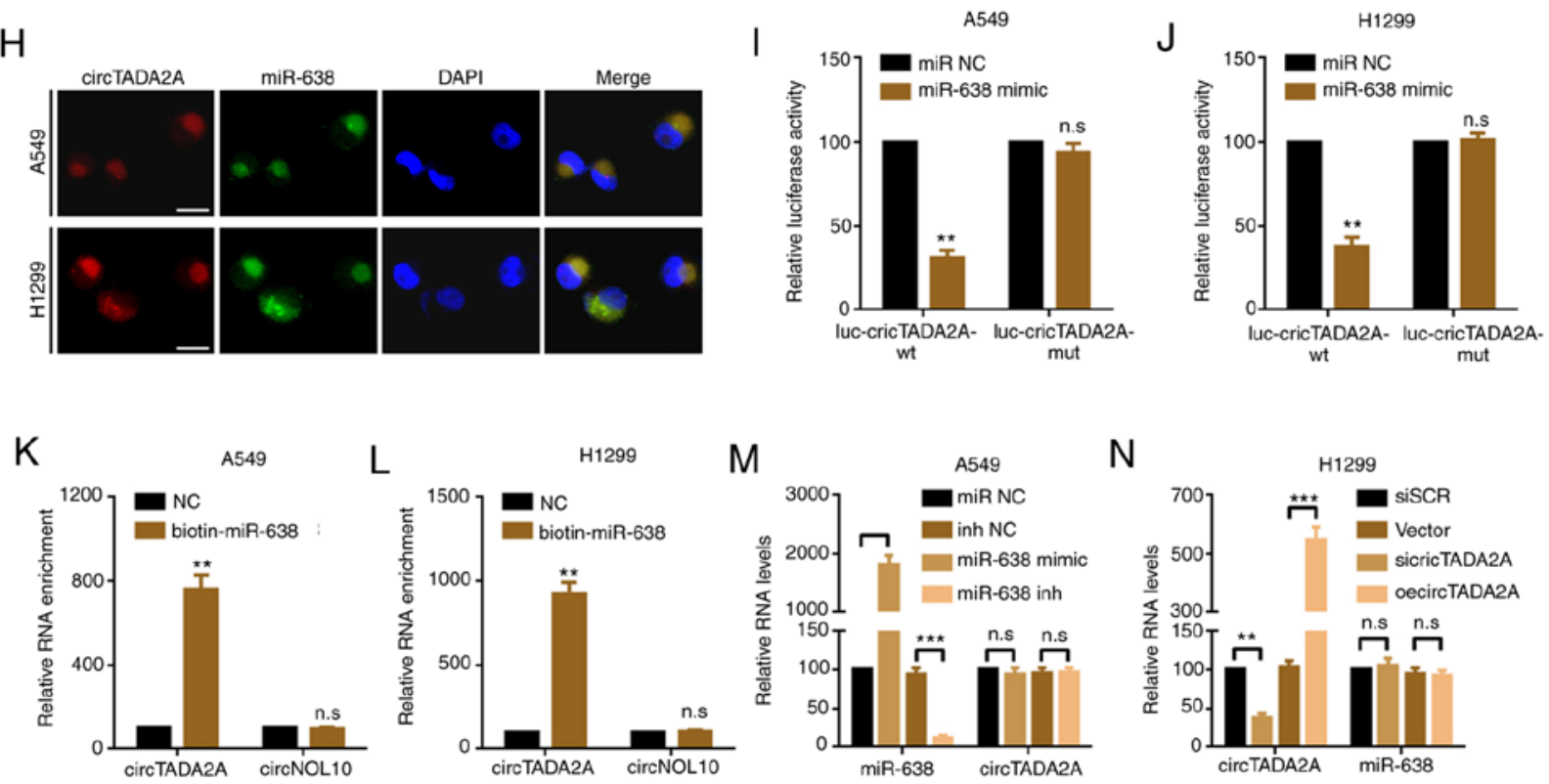

Figure 4. circTADA2A serves as a sponge for miR-638. (A) RNA immunoprecipitation experiments were performed using antibody against Ago2 on extracts from A549 and H1299 cells, and circTADA2A was enriched in the Ago2 group. ${ }^{* *} \mathrm{P}<0.01$. (B) Schematic illustration exhibiting overlap of target miRNAs of circTADA2A predicted by Circular RNA Interactome, as well as the miRNAs that were expressed at low levels in genome-wide studies GSE74190 and GSE19945. The expression of miR-638 in NSCLC was lower than that in normal lung tissue according to genome-wide studies (C) GSE74190 and (D) GSE19945. Expression of miR-638 in (E) NSCLC and paired adjacent non-tumor tissue and (F) cell lines was determined by RT-qPCR. ** P<0.01, ${ }^{* * *} \mathrm{P}<0.001$ vs. $16 \mathrm{HBE}$. (G) An inverse correlation between circTADA2A and miR-638 was demonstrated by Spearman correlation analysis. (H) Subcellular localization of circTADA2A and miR-638, as revealed by RNA-fluorescence in situ hybridization assay. The targeted binding effect between miR-638 and circTADA2A was confirmed by luciferase assay in (I) A549 and (J) H1299 cells. * ${ }^{* *}<0.01$ vs. miR-NC. Cell lysates from (K) A549 and (L) H1299 cells

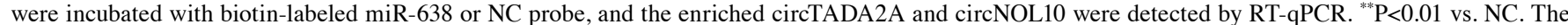
relative expression of circTADA2A and miR-638 in (M) A549 and (N) H1299 cells was measured by RT-qPCR. ${ }^{* *} \mathrm{P}<0.01,{ }^{* * * *} \mathrm{P}<0.001,{ }^{* * * *} \mathrm{P}<0.0001$. All data are shown as the mean $\pm \mathrm{SD}(\mathrm{n}=3)$. circTADA2A, circular RNA transcription adaptor 2A; RT-q, reverse transcription-quantitative; miR, microRNA; NSCLC, non-small cell lung cancer; Ago2, argonaute 2; NC, negative control; NOL10, nucleolar protein 10; wt, wild-type; mut, mutant; inh, inhibitor; SCR, scramble; oe, overexpression; n.s., not significant.

is derived from exons 5 and 6 of the TADA2A gene (15). The role of circTADA2A in cancer is not well known, and its function remains controversial. Wu et al (15) reported that circTADA2A is upregulated in osteosarcoma tissue specimens and cell lines and serves as a tumor promoter and increases malignant tumor behavior via miR-203a-3p/CREB3 signaling in osteosarcoma. In another study, Xu et al (14) found that circTADA2A is consistently and significantly decreased in a large cohort of patients with breast cancer, and its downregulation is associated with poor patient survival for triple-negative breast cancer. In the present study, the differentially expressed circRNAs in NSCLC were analyzed according to the GEO dataset GSE101586. It was found that circTADA2A was upregulated in five NSCLC tissue samples compared with paired paratumor tissue. RT-qPCR verification revealed that circTADA2A was upregulated in 38 NSCLC tissue samples 

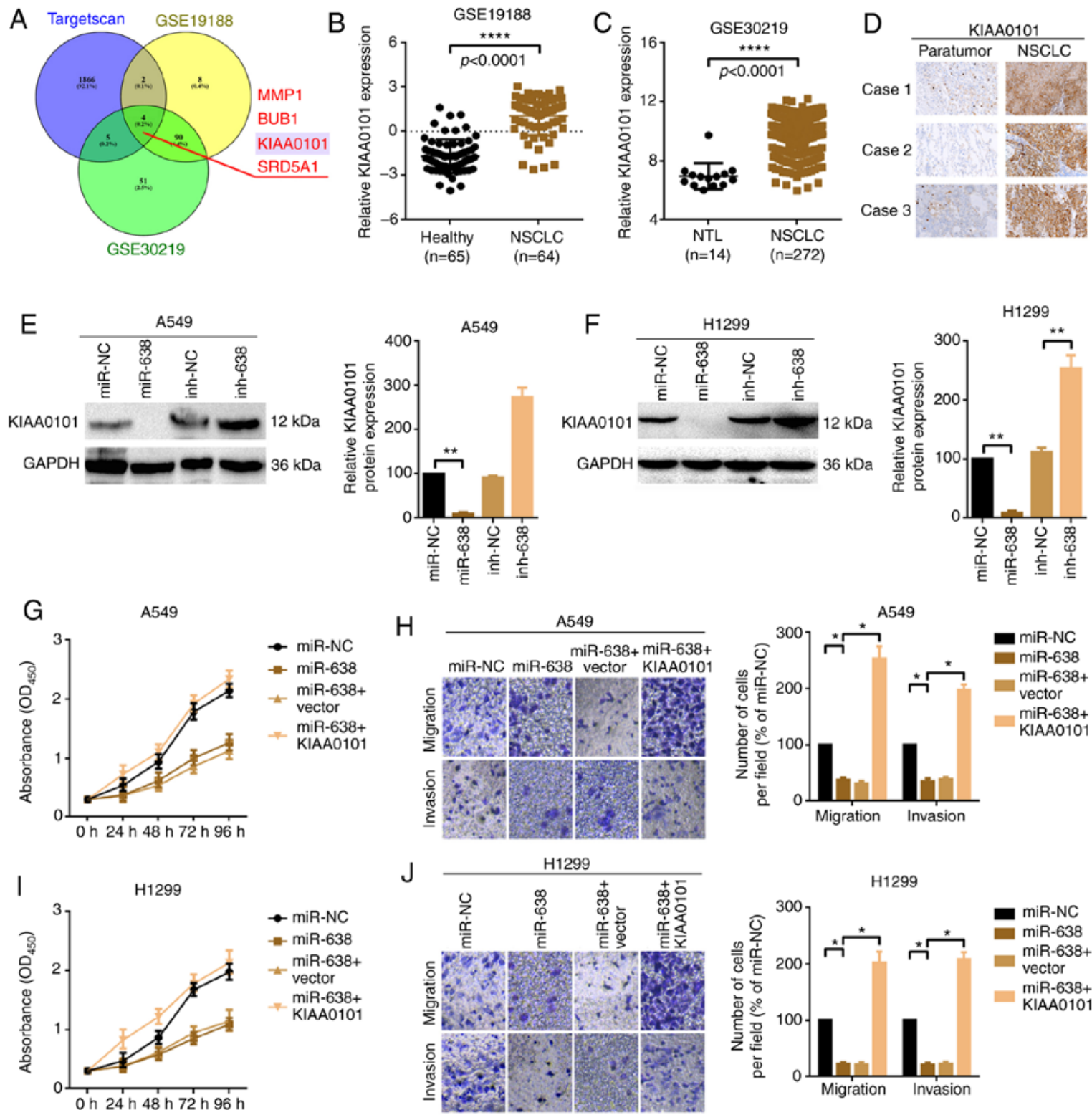

$\mathrm{K}$
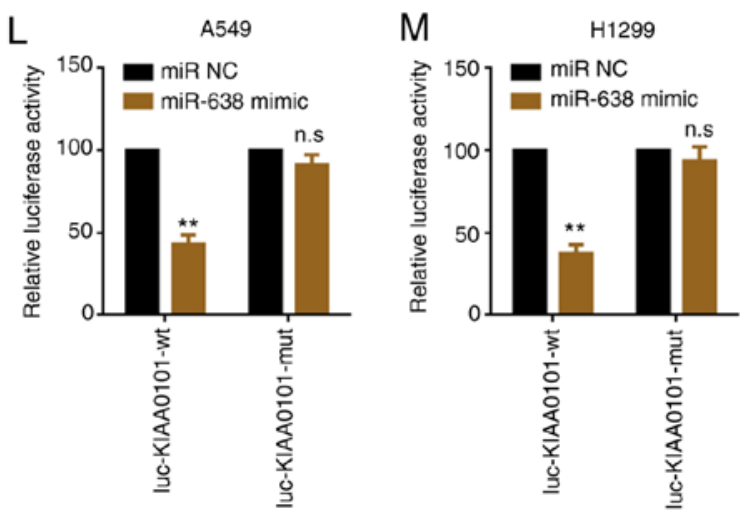

Figure 5. miR-638 suppresses proliferation and migration by targeting KIAA0101 in A549 and H1299 cells. (A) Schematic illustration exhibiting overlapping target mRNAs of miR-638 predicted by TargetScan and the mRNAs that were highly expressed in genome-wide studies GSE19188 and GSE30219. KIAA0101 expression in NSCLC tissues was higher than that in healthy and NTL tissue according to the results of genome-wide studies (B) GSE19188 and (C) GSE30219. ${ }^{* * * * *} \mathrm{P}<0.01$. (D) KIAA0101 expression in three NSCLC and paired paratumor tissue samples was evaluated by immunohistochemistry. KIAA0101 protein expression in (E) A549 and (F) H1299 cells following different miR-638 treatments was evaluated by western blot assay. ${ }^{* *} \mathrm{P}<0.01$. Proliferation of (G) A549 and (I) H1299 cells were determined by Cell Counting Kit-8 assay. Migration and invasion of (H) A549 and (J) H1299 cells were measured by Transwell assay. Magnification, $\mathrm{x} 20$; scale bar, $200 \mu \mathrm{m}$. "P<0.05. (K) Diagram of the constructed luciferase reporter plasmids. A luciferase assay was conducted to verify the targeted binding effect between miR-638 and KIAA0101 in (L) A549 and (M) H1299 cells. All data are presented as mean \pm SD (n=3). ${ }^{* *} \mathrm{P}<0.01$ vs. miR-NC. miR, microRNA; NSCLC, non-small cell lung cancer; KIAA0101, PCNA clamp associated factor; NTL, non-tumor lung; NC, negative control; BUB1, BUB1 mitotic checkpoint serine/threonine kinase; SRD5A1, steroid $5 \alpha$-reductase 1; inh, inhibitor; OD, optical density; wt, wild-type; mut, mutant; n.s., not significant. 

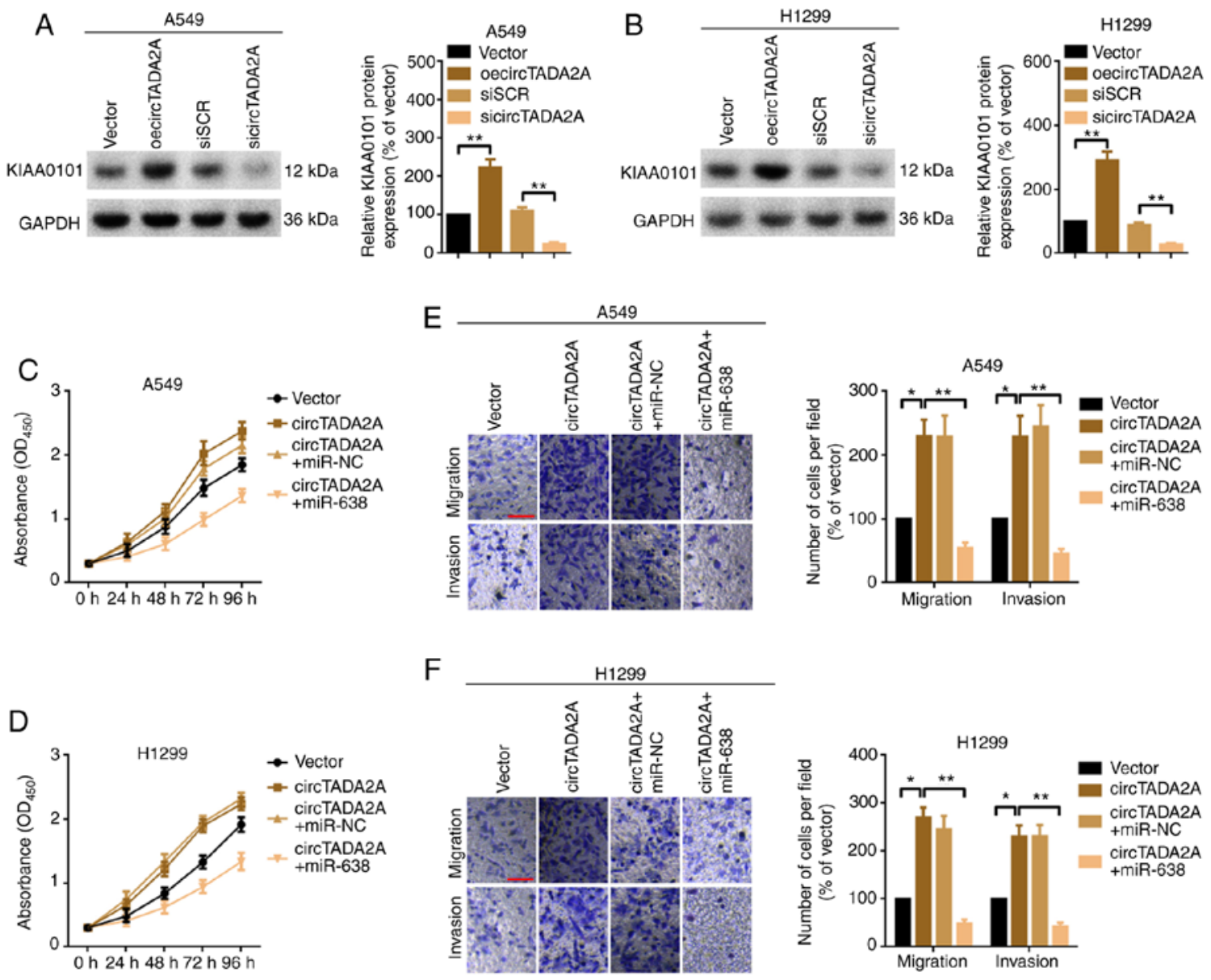

Figure 6. circTADA2A promotes cell proliferation and migration partially via the miR-638/KIAA0101 pathway in A549 and H1299 cells. KIAA0101 protein expression in (A) A549 and (B) H1299 cells following treatment with circTADA2A was evaluated by western blotting. Proliferation of (C) A549 and (D) H1299 cells, as determined by Cell Counting Kit-8 assay. Migration and invasion of (E) A549 and (F) H1299 cells were measured by Transwell assay. Magnification, $\mathrm{x} 20$; scale bar, $200 \mu \mathrm{m}$. All data are presented as the mean $\pm \mathrm{SD}(\mathrm{n}=3) .{ }^{*} \mathrm{P}<0.05,{ }^{* *} \mathrm{P}<0.01$. circTADA2A, circular RNA transcription adaptor $2 \mathrm{~A}$; KIAA0101, PCNA clamp associated factor; oe, overexpression; miR, microRNA; si, small interfering; SCR, scramble; NC, negative control.

and four NSCLC cell lines. CCK-8 and Transwell assays verified that circTADA2A promoted NSCLC cell proliferation and migration.

circRNAs function via multiple mechanisms, including serving as sponges of miRNAs and proteins, protein translation and derivation of pseudogenes (38). Since the majority of circRNAs are located in the cytoplasm and function as competitive endogenous (ce)RNAs for miRNAs, circRNA research has attracted attention $(39,40)$. Here, RNA-FISH assay demonstrated that circTADA2A and miR-638 were primarily located in the cytoplasm. miR-638, which is located at human chromosome $19 \mathrm{p} 13.2$, is a well-known tumor-suppressor miRNA that is implicated in multiple types of malignant tumor including hepatocellular carcinoma, breast, gastric, cervical and colon cancer, as well as glioma (41-46). Xia et al (47) reported that miR-638 is expressed at low levels in NSCLC, and downregulation of miR-638 promotes proliferation, invasion and epithelial-mesenchymal transition via SRY-box transcription factor 2 regulation in NSCLC. In the present study, miR-638 was downregulated in NSCLC according to analysis of the GEO datasets GSE74190 and GSE19945 and by RT-qPCR. Furthermore, the expression of miR-638 was negatively correlated with circTADA2A. Since the majority of circRNAs interact with miRNAs by serving as ceRNAs (48), the present findings indicate a biological basis for interaction between circTADA2A and miR-638, as both were localized in the cytoplasm. RNA pull-down and luciferase reporter assay confirmed that miR-638 targeted circTADA2A directly.

KIAA0101 interacts with several miRNAs, and is involved in cell cycle progression, cell proliferation, migration, metastasis and chemoresistance in multiple types of cancer $(4,49-51)$. In the present study, bioinformatics analysis and IHC detection revealed that KIAA0101 was highly expressed in NSCLC. CCK-8 and Transwell assays indicated that KIAA0101 was involved in miR-638-mediated cell proliferation and migration. Luciferase reporter assay found that KIAA0101 was a downstream target of miR-638. The ceRNA hypothesis proposes that mRNAs, transcribed pseudogenes and other RNA transcripts communicate via miRNA response elements (52). The present study indicated that circTADA2A communicated with KIAA0101 and regulated KIAA0101-mediated proliferation and migration of A549 and H1299 cells via miR-638.

In summary, the present study provides evidence that circTADA2A promoted proliferation and migration via regulation of the miR-638/KIAA0101 axis in NSCLC cells. circTADA2A and its downstream miR-638/KIAA0101 signaling pathway may be novel therapeutic targets for the molecular treatment of NSCLC. 


\section{Acknowledgements}

Not applicable.

\section{Funding}

The present study was supported by grants from Natural Science Foundation of Liaoning Province (grant no. 20180550318), Youth Talent Support Program of Liaoning Province (grant no. XLYC1907011), Key R\&D Program of Liaoning Province (grant no. 2018225014) and Technological Innovation Fund of Shenyang Technology Division (grant nos. RC190008 and 19-112-4-023).

\section{Availability of data and materials}

The datasets used and/or analyzed during the current study are available from the corresponding author on reasonable request.

\section{Authors' contributions}

XL and YW conceived the study. YZ, HY, YL and LY performed the experiments. XL and YZ confirmed the authenticity of all the raw data. $\mathrm{LZ}$ and JC analyzed the data. YW wrote the manuscript. All authors read and approved the final manuscript.

\section{Ethics approval and consent to participate}

The present study was approved by the Institute Research Medical Ethics Committee of Liaoning Cancer Hospital \& Institute. All participants provided written informed consent.

\section{Patient consent for publication}

Not applicable.

\section{Competing interests}

The authors declare that they have no competing interests.

\section{References}

1. Bray F, Ferlay J, Soerjomataram I, Siegel RL, Torre LA and Jemal A: Global cancer statistics 2018: GLOBOCAN estimates of incidence and mortality worldwide for 36 cancers in 185 countries. CA Cancer J Clin 68: 394-424, 2018.

2. Molina JR, Yang P, Cassivi SD, Schild SE and Adjei AA: Non-small cell lung cancer: Epidemiology, risk factors, treatment, and survivorship. Mayo Clin Proc 83: 584-594, 2008.

3. Lei H, Wang K, Jiang T, Lu J, Dong X, Wang F, Li Q and Zhao L: KIAA0101 and UbcH10 interact to regulate non-small cell lung cancer cell proliferation by disrupting the function of the spindle assembly checkpoint. BMC Cancer 20: 957, 2020.

4. Lv W, Su B, Li Y, Geng C and Chen N: KIAA0101 inhibition suppresses cell proliferation and cell cycle progression by promoting the interaction between $\mathrm{p} 53$ and Sp1 in breast cancer. Biochem Biophys Res Commun 503: 600-606, 2018.

5. Jain M, Zhang L, Patterson EE and Kebebew E: KIAA0101 is overexpressed, and promotes growth and invasion in adrenal cancer. PLoS One 6: e26866, 2011.

6. Tantiwetrueangdet A, Panvichian R, Sornmayura P, Leelaudomlipi S and Macoska JA: PCNA-associated factor (KIAA0101/PCLAF) overexpression and gene copy number alterations in hepatocellular carcinoma tissues. BMC Cancer 21: 295, 2021.
7. Fan S, Li X, Tie L, Pan Y and Li X: KIAA0101 is associated with human renal cell carcinoma proliferation and migration induced by erythropoietin. Oncotarget 7: 13520-13537, 2016.

8. Kato T, Daigo Y, Aragaki M, Ishikawa K, Sato M and Kaji M: Overexpression of KIAA0101 predicts poor prognosis in primary lung cancer patients. Lung Cancer 75: 110-118, 2012.

9. Patop IL, Wüst S and Kadener S: Past, present, and future of circRNAs. EMBO J 38: e100836, 2019.

10. Meng S,Zhou H, Feng Z, Xu Z, Tang Y, Li P and Wu M: CircRNA: Functions and properties of a novel potential biomarker for cancer. Mol Cancer 16: 94, 2017.

11. Rybak-Wolf A, Stottmeister C, Glazar P, Jens M, Pino N, Giusti S, Hanan M, Behm M, Bartok O, Ashwal-Fluss R, et al: Circular RNAs in the mammalian brain are highly abundant, conserved, and dynamically expressed. Mol Cell 58: 870-885, 2015.

12. Li C, Zhang L, Meng G, Wang Q, Lv X and Zhang J: Circular RNAs: Pivotal molecular regulators and novel diagnostic and prognostic biomarkers in non-small cell lung cancer. J Cancer Res Clin Oncol 145: 2875-2889, 2019.

13. Li Z, Yao H, Wang S, Li G and Gu X: CircTADA2A suppresses the progression of colorectal cancer via miR-374a-3p/KLF14 axis. J Exp Clin Cancer Res 39: 160, 2020.

14. Xu JZ, Shao CC, Wang XJ, Zhao X, Chen JQ, Ouyang YX, Feng J, Zhang F, Huang WH, Ying Q, et al: circTADA2As suppress breast cancer progression and metastasis via targeting miR-203a-3p/SOCS3 axis. Cell Death Dis 10: 175, 2019.

15. Wu Y, Xie Z, Chen J, Ni W, Ma Y, Huang K, Wang G, Wang J, Ma J, Shen S and Fan S: Circular RNA circTADA2A promotes osteosarcoma progression and metastasis by sponging miR-203a-3p and regulating CREB3 expression. Mol Cancer 18: 73, 2019.

16. Amin MB, Greene FL, Edge SB, Compton CC, Gershenwald JE, Brookland RK, Meyer L, Gress DM, Byrd DR and Winchester DP: The Eighth Edition AJCC Cancer Staging Manual: Continuing to build a bridge from a population-based to a more 'personalized'approach to cancer staging. CA Cancer J Clin 67: 93-99, 2017.

17. Zhong S, Wang J, Zhang Q, Xu H and Feng J: CircPrimer: A software for annotating circRNAs and determining the specificity of circRNA primers. BMC Bioinformatics 19: 292, 2018.

18. Chandrashekar DS, Bashel B, Balasubramanya SAH, Creighton CJ, Ponce-Rodriguez I, Chakravarthi BVSK and Varambally S: UALCAN: A portal for facilitating tumor subgroup gene expression and survival analyses. Neoplasia 19: 649-658, 2017.

19. Barrett T, Wilhite SE, Ledoux P, Evangelista C, Kim IF, Tomashevsky M, Marshall KA, Phillippy KH, Sherman PM, Holko M, et al: NCBI GEO: Archive for functional genomics data sets-update. Nucleic Acids Res 41: D991-D995, 2013.

20. Zeng K, Chen X, Xu M, Liu X, Hu X, Xu T, Sun H, Pan Y, He B and Wang S: CircHIPK3 promotes colorectal cancer growth and metastasis by sponging miR-7. Cell Death Dis 9: 417, 2018.

21. Zheng Q, Bao C, Guo W, Li S, Chen J, Chen B, Luo Y, Lyu D, Li Y, Shi G, et al: Circular RNA profiling reveals an abundant circHIPK3 that regulates cell growth by sponging multiple miRNAs. Nat Commun 7: 11215, 2016.

22. Wang Y, Lu Z, Wang N, Feng J, Zhang J, Luan L, Zhao W and Zeng $X$ : Long noncoding RNA DANCR promotes colorectal cancer proliferation and metastasis via miR-577 sponging. Exp Mol Med 50: 1-17, 2018.

23. Wang Y, Yang T, Liu Y, Zhao W, Zhang Z, Lu M and Zhang W: Decrease of miR-195 promotes chondrocytes proliferation and maintenance of chondrogenic phenotype via targeting FGF-18 pathway. Int J Mol Sci 18: 975, 2017.

24. Wang Y, Zeng X, Wang N, Zhao W, Zhang X, Teng S, Zhang Y and Lu Z: Long noncoding RNA DANCR, working as a competitive endogenous RNA, promotes ROCK1-mediated proliferation and metastasis via decoying of miR-335-5p and miR-1972 in osteosarcoma. Mol Cancer 17: 89, 2018.

25. Cheng Z, Yu C, Cui S, Wang H, Jin H, Wang C, Li B, Qin M, Yang $\mathrm{C}, \mathrm{He} \mathrm{J}$, et al: circTP63 functions as a ceRNA to promote lung squamous cell carcinoma progression by upregulating FOXM1. Nat Commun 10: 3200, 2019.

26. Qu S, Liu Z, Yang X, Zhou J, Yu H, Zhang R and Li H: The emerging functions and roles of circular RNAs in cancer. Cancer Lett 414: 301-309, 2018.

27. Dudekula DB, Panda AC, Grammatikakis I, De S, Abdelmohsen K and Gorospe M: CircInteractome: A web tool for exploring circular RNAs and their interacting proteins and microRNAs. RNA Biol 13: 34-42, 2016. 
28. Yu J, Xu QG, Wang ZG, Yang Y,Zhang L, Ma JZ, Sun SH, Yang F and Zhou WP: Circular RNA cSMARCA5 inhibits growth and metastasis in hepatocellular carcinoma. J Hepatol 68: 1214-1227, 2018.

29. Cai H, Liu X, Zheng J, Xue Y, Ma J, Li Z, Xi Z, Li Z, Bao M and Liu Y: Long non-coding RNA taurine upregulated 1 enhances tumor-induced angiogenesis through inhibiting microRNA-299 in human glioblastoma. Oncogene 36: 318-331, 2017.

30. Song YX, Sun JX, Zhao JH, Yang YC, Shi JX, Wu ZH, Chen XW, Gao P, Miao ZF and Wang ZN: Non-coding RNAs participate in the regulatory network of CLDN4 via ceRNA mediated miRNA evasion. Nat Commun 8: 289, 2017.

31. Nan A, Chen L, Zhang N, Jia Y, Li X, Zhou H, Ling Y, Wang Z, Yang C, Liu S and Jiang Y: Circular RNA circNOL10 inhibits lung cancer development by promoting SCLM1-mediated transcriptional regulation of the humanin polypeptide family. Ady Sci (Weinh) 6: 1800654, 2019.

32. Agarwal V, Bell GW, Nam JW and Bartel DP: Predicting effective microRNA target sites in mammalian mRNAs. Elife 4: e05005, 2015.

33. Anastasiadou E, Jacob LS and Slack FJ: Non-coding RNA networks in cancer. Nat Rev Cancer 18: 5-18, 2018.

34. Kristensen LS, Andersen MS, Stagsted LVW, Ebbesen KK and Hansen TB: The biogenesis, biology and characterization of circular RNAs. Nat Rev Genet 20: 675-691, 2019.

35. Salzman J: Circular RNA Expression: Its potential regulation and function. Trends Genet 32: 309-316, 2016.

36. Su M, Xiao Y, Ma J, Tang Y, Tian B, Zhang Y, Li X, Wu Z, Yang D, Zhou Y, et al: Circular RNAs in Cancer: Emerging functions in hallmarks, stemness, resistance and roles as potential biomarkers. Mol Cancer 18: 90, 2019.

37. Cui C, Yang J, Li X, Liu D, Fu L and Wang X: Functions and mechanisms of circular RNAs in cancer radiotherapy and chemotherapy resistance. Mol Cancer 19: 58, 2020.

38. Li X, Yang L and Chen LL: The biogenesis, functions, and challenges of circular RNAs. Mol Cell 71: 428-442, 2018

39. Yang Q, Li F, He AT and Yang BB: Circular RNAs: Expression, localization, and therapeutic potentials. Mol Ther 29: 1683-1702, 2021.

40. Zhong Y, Du Y, Yang X, Mo Y, Fan C, Xiong F, Ren D, Ye X, Li C, Wang Y, et al: Circular RNAs function as ceRNAs to regulate and control human cancer progression. Mol Cancer 17: $79,2018$.
41. Cheng J, Chen Y, Zhao P, Li N, Lu J, Li J,Liu Z, Lv Y and Huang C: Dysregulation of miR-638 in hepatocellular carcinoma and its clinical significance. Oncol Lett 13: 3859-3865, 2017.

42. Li M, Wang J and Liu H: Downregulation of miR-638 promotes progression of breast cancer and is associated with prognosis of breast cancer patients. Onco Targets Ther 11: 6871-6877, 2018.

43. Shen Y, Chen H, Gao L, Zhang W, He J, Yang X, Qin L, Xue X and Guo Z: MiR-638 acts as a tumor suppressor gene in gastric cancer. Oncotarget 8: 108170-108180, 2017.

44. Wei H, Zhang JJ and Tang QL: MiR-638 inhibits cervical cancer metastasis through $\mathrm{Wnt} / \beta$-catenin signaling pathway and correlates with prognosis of cervical cancer patients. Eur Rev Med Pharmacol Sci 21: 5587-5593, 2017.

45. Yan S, Dang G, Zhang X, Jin C, Qin L, Wang Y, Shi M, Huang H and Duan Q: Downregulation of circulating exosomal miR-638 predicts poor prognosis in colon cancer patients. Oncotarget 8 72220-72226, 2017.

46. Zheng DH, Wang X, Lu LN, Chen DL, Chen JM, Lin FM and Xu XB: MiR-638 serves as a tumor suppressor by targeting HOXA9 in glioma. Eur Rev Med Pharmacol Sci 22: 7798-7806, 2018.

47. Xia Y, Wu Y, Liu B, Wang P and Chen Y: Downregulation of miR-638 promotes invasion and proliferation by regulating SOX2 and induces EMT in NSCLC. FEBS Lett 588: 2238-2245, 2014.

48. Yu CY, Li TC, Wu YY, Yeh CH, Chiang W, Chuang CY and Kuo HC: The circular RNA circBIRC6 participates in the molecular circuitry controlling human pluripotency. Nat Commun 8: $1149,2017$.

49. Chen H, Xia B, Liu T, Lin M and Lou G: KIAA0101, a target gene of miR-429, enhances migration and chemoresistance of epithelial ovarian cancer cells. Cancer Cell Int 16: 74, 2016

50. Jain N, Roy J, Das B and Mallick B: miR-197-5p inhibits sarcomagenesis and induces cellular senescence via repression of KIAA0101. Mol Carcinog 58: 1376-1388, 2019.

51. Samantarrai D and Mallick B: miR-429 inhibits metastasis by targeting KIAA0101 in soft tissue sarcoma. Exp Cell Res 357: 33-39, 2017.

52. Salmena L, Poliseno L, Tay Y, Kats L and Pandolfi PP: A ceRNA hypothesis: The rosetta stone of a hidden RNA language? Cell 146: 353-358, 2011

This work is licensed under a Creative Commons Attribution-NonCommercial-NoDerivatives 4.0 International (CC BY-NC-ND 4.0) License. 